\title{
Cattle eradication and malnutrition in under five's: a natural experiment in Botswana
}

\author{
Eelco Boonstra ${ }^{1,2, *}$, Morten Lindbæk ${ }^{1}$, Boga Fidzani ${ }^{3}$ and Dag Bruusgaard ${ }^{1}$ \\ 'Institute of General Practice and Community Medicine, University of Oslo, PO Box 1130, Blindern, N-0317 Oslo, \\ Norway: ${ }^{2}$ Present address: Nordic Clinic, P.O. Box 72185, Dar es Salaam, Tanzania: ${ }^{3}$ Department of Agricultural \\ Planning \& Statistics, Ministry of Agriculture, PB 003 Gaborone, Botswana
}

Submitted 20 June 2000: Accepted 18 January 2001

\begin{abstract}
Background: An outbreak of contagious bovine pleuropneumonia (CBPP) in the northern part of Botswana in 1996 was contained through eradication of all heads of cattle in Ngamiland district (Ngami East and West) in the period April 1996 to February 1997. This disaster posed a serious threat to those who depended on the livestock sector for sustenance and to the nutrition security of the population, especially the under five's.

Aim: The aim of this study was to assess the impact of the cattle eradication on the nutritional status of children.

Method: A secondary analysis of existing data from the Botswana National Nutrition Surveillance System enabled us to study the impact of this disaster on malnutrition in the under five's by comparing quarterly malnutrition rates for Ngami East with national figures for the period of January 1995 to March 1998.

Results: While the risk for malnutrition among under five's in Ngami East increased from 0.046 to 0.105 during the study period, giving a relative risk of 2.299 , the increase in risk for Botswana was from 0.133 to 0.139 , giving a relative risk of 1.048 . The attributable risk for cattle eradication impact on malnutrition was $4.6 \%$ for Botswana and $54.4 \%$ for Ngami East.

Conclusion: The cattle eradication impacted seriously on the food and nutrition security of the under five's in Ngami East, compared with the country as a whole.
\end{abstract}

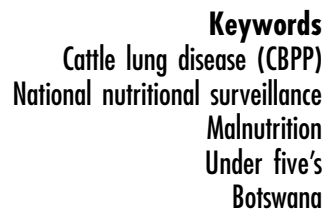

Contagious bovine pleuropneumonia (CBPP) in cattle is one of the major threats to cattle health and production in Africa. This disease is present in 24 countries of tropical Africa ${ }^{1}$. An outbreak of CBPP was detected in the extreme northern part of Botswana in 1995 after more than half a century of freedom from the disease.

CBPP is a respiratory disease characterised by pneumonia and pleurisy ${ }^{2}$. During the early containment stage of the CBPP outbreak (from February 1995 to the end of March 1996), 32600 cattle were killed in Ngami West. Despite control measures the disease continued to spread from Ngami West to Ngami East. When the outbreak intensified, the Government resorted to an eradication campaign in both Ngami West and East, which was carried out from April 1996 to February 1997. The total number of beasts killed was about 320 000. By September 1996, 292990 head of cattle (92\%) had already been destroyed $^{3}$.

Before the eradication widespread concern was expressed over possible effects on the social welfare of the population of this district, since cattle play a vital role in the socio-economic and cultural lives of the district's people. Botswana's mainly rural population is heavily dependent on cattle for their day-to-day needs like milk, meat, transport, draught power, and culturally important ceremonies such as weddings and funerals. The food security situation of many rural and urban households is also partly dependent on arable agriculture. However, due to regular droughts, arable agriculture is difficult and yields are unpredictable.

In order to minimise the effect of this eradication and to reduce social disruption and economic dislocation, Government established a multi-sectoral Reference Group both at national and district level. Their main responsibility was to co-ordinate implementation of the relief programme, as well as oversee payment of compensation to residents for their destroyed cattle.

Coincidentally, the district and the country as a whole had been declared drought-stricken in both June 1997 and June 1998. While the national average malnutrition 
rate in under five's remained stable at about 13.5\% in 1995 and 1996, it had increased to $18.4 \%$ in $1997^{4}$.

\section{Characteristics of the district ${ }^{5}$}

Ngami East is the part of Ngamiland mostly dependent on cattle. The estimated population as at 1 January 1997 was 62400 . The district headquarters is in Maun, which is the gateway to the famous Okavango Delta. The remaining villages are dispersed throughout the district. The main livelihood in the district is cattle farming. The Botswana Meat Commission abattoir in Maun, which used to slaughter cattle for the Ngamiland area, was closed in 1996 as a result of the disaster. Subsistence arable agriculture is practised in most of the settlements, although this is heavily constrained by poor soils and drought.

The aim of this paper was to assess the impact of the eradication of cattle on malnutrition in children.

\section{Materials and methods}

\section{Nutrition surveillance}

The National Nutrition Surveillance System (NNSS) was introduced in $1978^{6}$ at all primary health care facilities in the country. Data collection for all children under 5 years of age is carried out primarily by Family Welfare Educators at local health facilities. The weight is plotted on a 'Road-to-Health' chart against the Harvard growth curves and analysis is made as to whether a child is moderately or severely malnourished. Moderate malnutrition is defined as a weight-for-age between the 60th and 80th percentile. Severe malnutrition is defined as weightfor-age below the 60th percentile. Underweight is coded on tally sheets as either ' 1 ' (moderate malnutrition) or ' 2 ' (severe malnutrition). In this study these are summed together as total malnutrition. A third parameter, which is registered within the NNSS, is growth failure. This measure is utilised to flag a child who is not growing as expected, when a child's weight has not been increasing during a period of at least two months. The 'Road-toHealth' chart shows graphically how, in a community experiencing acute nutritional distress, growth failure rates increase first, followed by moderate and severe malnutrition rates.

The health facility staff prepares a summary of the NNSS data. This is then passed to the district level where summary tables for the whole district are prepared. Centrally, the NNSS is compiled into Quarterly National NNSS Reports to monitor the country-wide situation. Reports are sent to the Food and Nutrition Unit of the Ministry of Health.

At district level the NNSS data are utilised by the District Development Committees influencing numerous droughtrelief decisions. At national level the data are utilised by the Inter-Ministerial Drought Committee, which tours the districts yearly in non-drought years and more frequently in a drought year. The Food and Nutrition Unit of the Ministry of Health utilises the information generated to address policy, planning and programming issues. The Unit also reports findings to the National Early Warning Technical Committee. NNSS results thus influence decision-making throughout the chain of political events.

\section{Material}

We have compiled quarterly total malnutrition and growth failure rates of under five's for Ngami East, and compared them with national figures as reference during the period of January 1995 to March 1998.

From April 1998 the NNSS based their anthropometric measurements on international reference values defined by the US National Center for Health Statistics ${ }^{7,8}$. Therefore, March 1998 was chosen as the end point for this study.

\section{Results}

\section{Malnutrition rates before and after cattle eradication in Ngami East}

Average quarterly attendance rates for under five's attending Child Welfare Clinics in Ngami East during the study period varied from $77.8 \%$ to $86.4 \%{ }^{9}$ and for Botswana from $62.5 \%$ to $76.5 \%{ }^{10}$.

Figure 1 compares total malnutrition rates in Ngami East district with national figures from 1991 to 1997. District total malnutrition rate was less than half of the national rate in the period 1991 to 1993. Between 1994 and 1995, total malnutrition rate in Ngami East actually fell to about a third of the national rate. However, while the national rate stood at near 13\% in 1995 and 1996, the rate for Ngami East more than doubled in the same period: from $4.1 \%$ in 1995 to $8.9 \%$ in 1996 . Further, while the increase from 1995 to 1997 on the national level represented $44 \%$, the rate at the district level almost tripled in the same period.

Figure 2 compares Ngami East district and national malnutrition rates on a quarterly basis. The rate shows a steep increase for the district from the second quarter of 1996, peaking during the fourth quarter of 1996 for the district. The national rate first started to increase from the

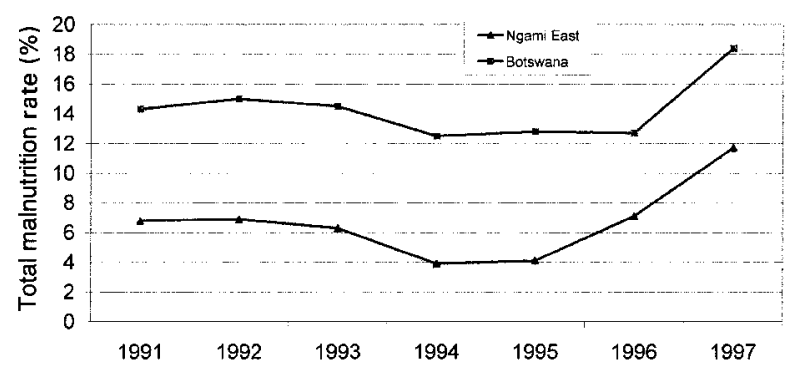

Fig. 1 Total malnutrition rates in under five's in Ngami East district and Botswana by year, 1991 to 1997 


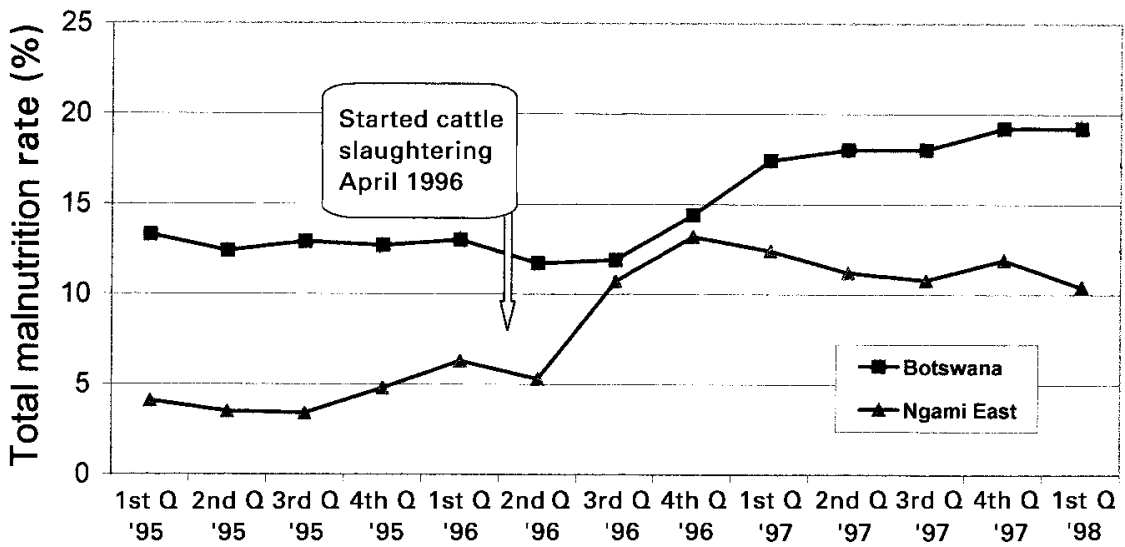

Fig. 2 Total malnutrition rates in under five's in Ngami East district and Botswana by quarter of year, first quarter of 1995 to first quarter of 1998

third quarter of 1996. While the increase from the second to the fourth quarter in 1996 for the district was 150\%, the increase in national rate for the same period was $23 \%$. However, the national rate continued to increase gradually to $19.2 \%$ for the first quarter of 1998 . The district rate had by then decreased to $10.4 \%$, which was still about twice the pre-CBPP figure.

Figure 3 compares the trends in growth failure rates for Ngami East and Botswana from the first quarter of 1995 to the first quarter of 1998. The increase in growth failure rate from the first quarter of 1996 to the fourth quarter of the same year for Ngami East and Botswana was 110\% and $7 \%$, respectively.

\section{Relative and attributable risks for Ngami East and Botswana}

Table 1 shows the number and percentage of children under five with malnutrition and growth failure in Ngami East and the rest of Botswana by quarter during the study period. These figures are the basis for calculation of the relative risk $(R)$ for malnutrition. First we calculated the average baseline risk based on the data from the first quarter of 1995 to the first quarter of 1996, before the cattle were eradicated. We found for Ngami East $R_{\mathrm{N} 1}=$ 0.046 and for the rest of Botswana $R_{\mathrm{B} 1}=0.133$.

Then we calculated the relative risk for malnutrition in the year during and after eradication of the cattle, from the second quarter of 1996 to the first quarter of 1997, as shown in Table 2 . We found for Ngami East $R_{\mathrm{N} 2}=0.105$ and for the rest of Botswana $R_{\mathrm{B} 2}=0.139$. The risk ratios for Botswana and Ngami East were calculated with the following formula: $R R=$ risk after/risk before, giving $R R_{\mathrm{B}}=$ 1.048 for Botswana and $R R_{\mathrm{N}}=2.299$ for Ngami East. Furthermore, we calculated the attributable risk according to the following formulas:

$$
R R_{\mathrm{AN}}=R R_{\mathrm{N}}-R R_{\mathrm{B}} / R R_{\mathrm{N}}
$$

and

$$
R R_{\mathrm{AB}}=R R_{\mathrm{B}}-1 / R R_{\mathrm{B}},
$$

giving the attributable risk of $4.6 \%$ for Botswana and $54.4 \%$ for Ngami East. This means that $54.4 \%$ of the rise of malnutrition in Ngami East is caused by the cattle eradication, and the rest is caused by other factors. This is based on the assumption that other risk factors had the

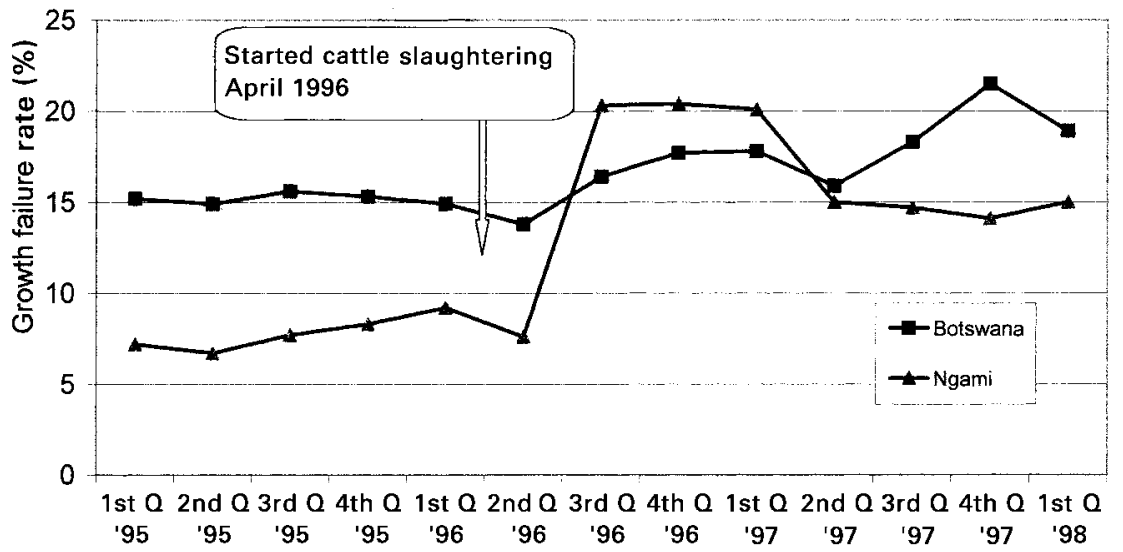

Fig. 3 Growth failure rates in under five's in Ngami East district and Botswana by quarter of year, first quarter of 1995 to first quarter of 1998 
Table 1 Malnutrition and growth failure* in children under five years in Ngami East and rest of Botswana by time period $\dagger$

\begin{tabular}{|c|c|c|c|c|c|c|c|}
\hline \multirow[b]{2}{*}{ Time perioc } & & \multicolumn{3}{|c|}{ Ngami East } & \multicolumn{3}{|c|}{ Botswana } \\
\hline & & Malnutrition (\%) & Growth failure (\%) & Total & Malnutrition (\%) & Growth failure (\%) & Total \\
\hline \multirow[t]{5}{*}{ Period 1} & $1995^{1}$ & $277(4.1)$ & $486(7.2)$ & 6754 & $19972(13.7)$ & 22115 (15.2) & 1454 \\
\hline & $1995^{2}$ & 279 (3.7) & $506(6.7)$ & 7549 & 18867 (12.8) & 21885 (14.9) & 1468 \\
\hline & $1995^{3}$ & 278 (3.7) & $580(7.7)$ & 7527 & 19082 (13.3) & 22237 (15.6) & 1425 \\
\hline & $1995^{4}$ & 367 (4.9) & $621(8.3)$ & 7482 & 18969 (13.1) & 22149 (15.3) & 1447 \\
\hline & $1996^{1}$ & $467(6.3)$ & $674(9.2)$ & 7359 & $18477(13.4)$ & 20616 (14.9) & 1383 \\
\hline \multirow{4}{*}{ Period 2} & $1996^{2}$ & 395 (5.3) & $567(7.6)$ & 7507 & $18971(12.0)$ & 21805 (13.8) & 1580 \\
\hline & $1996^{3}$ & 787 (10.7) & 1497 (20.3) & 7351 & 19065 (12.0) & 26153 (16.4) & 1594 \\
\hline & $1996^{4}$ & 995 (13.2) & 1539 (20.4) & 7534 & 22965 (14.5) & 28117 (17.7) & 158854 \\
\hline & $1997^{1}$ & 937 (12.7) & $1482(20.1)$ & 7371 & $25100(17.6)$ & 25323 (17.8) & 142269 \\
\hline
\end{tabular}

* Number of children, with corresponding percentage in parentheses.

† Superscript numbers indicate the quarter considered.

same influence in Ngami East as in the rest of Botswana. Finally, the 95\% confidence interval (CI) was calculated for the proportions and attributable risks ${ }^{11}$.

The measurements of malnutrition were to a great extent based on repeated measurements of the same individuals. To account for this, we calculated confidence intervals in a conservative way by using only one measurement before and after cattle eradication. The calculation of risks is based on pooled data.

\section{Discussion}

\section{Methods}

The validity of nutritional surveillance figures can be affected by many factors operating at district and national levels: the type of staff, regularity of training of health staff, improper calibration of weighing scales, and accuracy of entering data in the tally sheets and from there into the district's Nutrition Logbook. This was used as the source of information for the district monthly and quarterly reports, which were sent to the Ministry of Health.

At the time of the cattle eradication, Botswana had 28 years of experience with the NNSS, refining and improving this system regularly. Primary health care staff throughout Botswana are familiar with this system and are kept updated. In order to improve the quality of the data, District Health Education and Nutrition Officers (DHENOs) were trained and attached to the District
Health Teams. Fortunately Ngami East was one of the few districts that had a DHENO during the time covered by this study.

In Ngami East weighing of under five's was mainly carried out by Family Welfare Educators, but sometimes carried out by non-trained staff, especially during staff shortages. In order to safeguard the quality of nutrition surveillance data collected during the cattle eradication, the DHENO arranged a workshop for nurses and Family Welfare Educators, which was held in June 1996. This workshop also addressed calibration of weighing scales and accuracy of entering data into the monthly tally sheets. The DHENO also carried out continuous in-service training and monitoring of the quality of the monthly tally sheets with nutritional data from the health facilities. The nurse in charge of each of the district's 19 primary health care facilities was responsible for the day-to-day supervision of the weighing and recording of the data. All of these measures contributed to ensure the quality of the nutrition surveillance data.

Since malnutrition rates among under five's represented one of several indicators that helped secure increased relief aid from the Government, one could not rule out that an expected increase in malnutrition in Ngami East could lead to over-reporting by the Family Welfare Educators in these areas. The main author of this study was, as Senior District Medical Officer, in charge of the primary health care services of Ngami East district during the study period and responsible for the implementation

Table 2 Calculation of risk for malnutrition in Ngami East and the rest of Botswana

\begin{tabular}{lll}
\hline & \multicolumn{1}{c}{ Ngami East } & \multicolumn{1}{c}{ Botswana } \\
\cline { 2 - 3 } & \multicolumn{1}{c}{ Risk $(95 \% \mathrm{Cl})$} & Risk $(95 \% \mathrm{Cl})$ \\
\hline Relative risk period 1 & 0.0455 & 0.1328 \\
Relative risk period 2 & 0.1046 & 0.1392 \\
Proportion $R_{2} / R_{1}$ & $2.299(2.019-2.618)$ & $1.048(1.028-1.068)$ \\
Attributable risk & $0.5441^{* \star}(0.481-0.600)$ & $0.0458^{*}(0.027-0.069)$ \\
\hline * Attributable risk calculated by comparison with $R R_{\mathrm{B}}$ in period 1. & \\
${ }^{* *}$ Attributable risk calculated by comparison with attributable risk in Botswana in period 2.
\end{tabular}


of the NNSS in the district. Regular follow-ups by him and the education and nutrition officer did not reveal such biased reporting.

\section{Malnutrition in under five's in the district}

Malnutrition rates for Ngami East had been the lowest in the country for many years. Since 1996 Ngami East lost this place. Until the cattle were eradicated total malnutrition rates were less than half the national figures. While the drought in Botswana in 1997 and 1998 contributed to a moderate increase in malnutrition rate in the country as a whole, the combined effect of drought and cattle eradication in Ngami East resulted in a two- to threefold increase of total malnutrition rate.

The 36\% increase in the total malnutrition rate of under five's in Botswana as a whole was mainly the result of the drought, which struck all districts. No major factors other than drought seem to have been operating in the country as a whole, including Ngamiland. In the same period the increase in total malnutrition rate in Ngami East was 185\%. It is therefore possible to assume a considerable relative contribution of the cattle eradication to the increase in malnutrition rates in Ngami East.

The fact that the malnutrition rate in Ngami East started to increase several months before the national malnutrition rate showed an upward trend lends support to the belief that the eradication of cattle had a dramatic impact on the malnutrition rate in this district.

\section{Malnutrition in Ngami East}

The significant drop in malnutrition rate in Ngami East since April 1997 is most likely the result of many factors operating together:

1. Many households coped with the disaster by changing from cattle farming to arable agriculture or found new livelihoods ${ }^{12}$.

2. A CBPP Food Relief Programme guaranteed the supply of food rations to about $80 \%$ of the beneficiaries on a monthly basis.

3. A range of Government programmes aimed at improving the level of employment and incomes, such as the Labour Intensive Public Works Programme.

4. A team including members from the District Health Team toured the district addressing popular ('kgotla') meetings on issues of child care, feeding of the under five's, alcohol misuse and child neglect ${ }^{13}$.

5. In some places, direct feeding of under five's, which had been stopped in 1993 throughout the country, was reintroduced in order to ensure that under five's benefited directly from supplementary food.

Although growth failure and total malnutrition rates dropped gradually after peaking at the fourth quarter of 1996 and the third quarter 1997, respectively, at the end of the survey period (March 1988) these rates were still far above the pre-CBPP rates.

Participation in the Food Ration Programme in the district was quite high ( $44 \%$ of households) ${ }^{12}$, higher than participation in the Labour Intensive Public Works programme (21\%) that was meant to provide extra income to households.

The outbreak of CBPP triggered numerous changes in the pattern of life in the district. For example, many people migrated from cattle posts to either lands or villages. The majority of the households who opted for compensation for the loss of their cattle used the cash for routine household expenditure to meet their immediate needs ${ }^{12}$. Many of them were not able to restock and will continue to experience the impacts of CBPP for many years to come. Ownership of cattle in 1998 was more skewed than ever before ${ }^{12}$. The factors mentioned above may explain why malnutrition figures by March 1998 had not come down to pre-CBPP rates. Arable farming had by then overtaken cattle as the major source of livelihood in Ngami East, although periods of drought make food production unpredictable. Income-generating projects have been put in place to reduce unemployment and diversify the basis for the district's economy.

\section{Conclusion}

Available data from the NNSS indicate that the eradication of cattle in Ngami East posed a serious threat to food and nutrition security in the area and contributed to a significant increase in malnutrition rates in the under five's, compared with the country as a whole.

It is assumed that malnutrition rates could have risen higher without the Food Relief Programme that the Government of Botswana put in place as part of a multi-sectoral response aimed at reducing the impact of this disaster at the social, community and household level ${ }^{12}$.

\section{Acknowledgements}

We thank Associate Professor Håkon Gjessing for statistical advice and Professor Dag Thelle for constructive comments on the article, both co-workers at the Department of General Practice and Community Medicine, University of Oslo.

\section{References}

1 Masiga WN, Domenech J, Windsor RS. Manifestation and epidemiology of contagious bovine pleuropneumonia in Africa. Rev. Sci. Tech. 1996; 15(4): 1283-308.

2 Amanfu W, et al. An outbreak of contagious bovine pleuropneumonia in Ngamiland district of northwestern Botswana. Vet. Rec. 1998; 143(2): 46-8.

3 Ministry of Agriculture. CBPP Eradication Programme 
Report, 3-10 September 1996. Botswana: Department of Animal Health and Production, Ministry of Agriculture, 1996.

4 Drought Declaration by His Excellency the President $\mathrm{Mr}$ Festus G. Mogae, June 1998.

5 Ngami District Council. Ngamiland District Development Plan 5: 1997-2003. Gaborone, Botswana: Ngami District Council, 1997.

6 Ministry of Health. Report of Consultancy to Review and Revise The Botswana National Nutrition Surveillance System. Gaborone, Botswana: Food and Nutrition Unit, Family Health Division, Ministry of Health, 1993.

7 World Health Organization (WHO). Measuring Change in Nutritional Status. Guidelines for Assessing the Nutritional Impact of Supplementary Feeding Programmes for Vulnerable Groups. Geneva: WHO, 1983.
8 World Health Organization (WHO). Global Nutritional Status. Anthropometric Indicators. Geneva: WHO, 1997.

9 Nutrition Logbook Ngami East, 1995-98.

10 Ministry of Health. Quarterly Reports of the National Nutrition Surveillance System. Gaborone, Botswana: Food and Nutrition Unit, Ministry of Health, first quarter 1996 to first quarter 1998.

11 Rothman KJ, Greenland S. Modern Epidemiology, 2nd ed. Philadelphia, PA: Lippincott-Raven, 1998; 295.

12 Fidzani B, Mlenga WS, Atlhopeng M, Shatera MM. Socioeconomic Effects of CBPP in Ngamiland. Gaborone, Botswana: Division of Agricultural Planning \& Statistics, Ministry of Agriculture, 1999.

13 Boonstra E. Rapid assessment of malnutrition in under fives in Sehithwa. J. Dent. E Med. Assoc. Botswana 1996; (March). 